\title{
Sexism in News: A Comparative Study on the Portray of Female and Male Politicians in The New York Times
}

\author{
Haoyun Dai, Xiaodong Xu* \\ School of Foreign Languages and Cultures, Nanjing Normal University, Nanjing, China \\ Email: ${ }^{*}$ xiaodong $x @$ njnu.edu.cn
}

Received 7 October 2014; revised 25 November 2014; accepted 8 December 2014

Copyright (C) 2014 by authors and Scientific Research Publishing Inc.

This work is licensed under the Creative Commons Attribution International License (CC BY). http://creativecommons.org/licenses/by/4.0/

\section{(c) (i) Open Access}

\begin{abstract}
Adopting a comparative and descriptive case study of The New York Times, this paper aims to probe into the gender discrimination against female politicians in the news media. The New York Times, one of the most authoritative newspapers in the world, can be a convincing representative to expose the universal ideologies like sexism in the news media. The authors attempt to analyze the sexism in news from two dimensions, namely, horizontal dimension (synchronic) and vertical dimension (diachronic). Horizontally, the news reports concerning Barack Hussein Obama and Hillary Diane Rodham Clinton, two rivals of the Democratic Party in the 2008 American presidential election, are chosen. By analyzing the difference in speech reporting, it can be seen that female politicians' speeches are more controlled and interfered. Vertically, based on Markedness Theory, we explore the development and change in formal marking, distributional marking and semantic marking. It is observable that in spite of the current subtle sexism hidden in news reports, news media have made great efforts in preventing gender discrimination over the past century and sexism against women in the current news reports appears to be less direct and more subtle compared with the past.
\end{abstract}

\section{Keywords}

Sexism, The New York Times, Speech Reporting, Markedness Theory

\section{Introduction}

\subsection{Background and Researching Purpose}

Since the feminist movement in 1960s, sexism has been an important research subject for both sociologists and ${ }^{*}$ Corresponding author.

How to cite this paper: Dai, H. Y., \& Xu, X. D. (2014). Sexism in News: A Comparative Study on the Portray of Female and Male Politicians in The New York Times. Open Journal of Modern Linguistics, 4, 709-719. 
linguists. According to Sapir-Whorf Hypothesis, language not only comes into being under the influence of society and culture but also affects people's perceptions of reality and the world in return (Sapir, 1986). News, as one of the pragmatic uses of language, shares the same attribution: shaped by and reshape society. Presently, as news media has become the major channel for people to obtain authoritative information, feminist media researches enter a prosperous stage and draw the attention both at home and abroad.

As mentioned above, news and languages are the carriers as well as the creators of social culture, reflecting and at the same time reinforcing the ideology of the public. Studying sexism from the perspective of news media provides us with a clearer and more direct way to detect the asymmetrical power distribution between females and males. Through this study, the authors hope to arouse people's awareness of the hidden sexism which may put women in a disadvantaged position and proposes some current trends of sexism in news media which are well on their way to gender equality. Specifically, this study has two goals: firstly, by the contrastive study of the data collected from The New York Times, this study was conducted to probe into the questions of how power distribution is manipulated by different modes of speech reporting. Secondly, to explore the development and evolvement of sexist language in news through the past century and detects positive changes in gender equality.

\subsection{Literature Review}

The previous studies of language and gender generally focus on two aspects: one is to study linguistic sexism in language itself from the perspective of morphology, syntax, semantics etc. The other is to study gender difference in terms of pragmatics, discourse modes, speech styles and so on.

Jesperson is the pioneer in the study of language and gender. His book Language: It's Nature, Development and Origin analyzes the features of language used by women in terms of their vocabulary and sentence structures. In his book The Philosophy of Grammar he pointed out that words like liar, neighbor, stranger etc. can be used to refer to both women and men, while words regarding profession like lawyer can only denote male information. Jesperson (1923) also remarked that English is the most sexist language he has ever known. Since the second wave of feminist movement started in 1960s, gender differences in language have been questioned and challenged. More and more sociolinguists get involved in the study of sexism in language. Robin Lakoff's Language and Women's Place (1975) is generally regarded as the most influential work at that time, because it pioneers in the systematic study of linguistic sexism and turns the sexist language study to a reexamination of the differences between men's and women's languages. She noted that women are oppressed by sexist language at two levels: the process of learning language and the negative influence of acquired language imposed on them. By analyzing the vocabulary, sentence patterns and tones regularly used by women, Lakoff (1975) pointed out that the language used by women puts them at a disadvantaged position, which will gradually result in their lower social position and weakened discourse power. Further studies were made on the gender-language issue during 1980s and 1990s. Spender (1980) claimed language as a powerful instrument of patriarchy which contributed to women's oppression. It is worth mentioning that the meeting held by International Linguistic Association in 1999 chose "language and gender" as its theme. This indicates that gender-language issue has become an important issue in the field of linguistic studies.

With the development of information technology, extensive attention has been captured by the issue of media and gender. The fourth World Conference on Women held in 1995 pointed out that media had been degrading women by constantly presenting negative images and ignoring their contributions to society. Some case studies were made on the reports concerning specific incidents of sexism such as the sexist behaviors emerged in stories about footballers (Attenborough, 2013, 2014; Toffoletti, 2007). They found that the representation and recontextualization manipulated by reporters undermined the legitimacy of complaints towards these misbehaviors. Other studies probed into the influence of sexist media information on women and children. For example, Megarry (2014) proposed that online sexual harassment excludes women's voice from the digital public sphere. Steyer (2014) found that traditional portrayals of women were still common in media, which would negatively affect children's development. One of particular relevant study conducted by Wright and Holland (2014) investigated the media portrayals of Julia Gillard's speech "sexism and misogyny". In this study, three principal gendered framings were found to be responsible for limiting the salience of Gillard's speech: strategic attack, uncontrolled emotional outpouring and hypocrisy, which would further differentiate females from political leadership (Wright \& Holland, 2014). The discourse analysis method adopted by the authors proves to be an effective tool in revealing sexism. Furthermore, it would be more convincing if comparisons can be made with the portrayal of 
another male leader's speech.

The study of gender-language relation in China began in the late 1970s and early 1980s. With the opening up of China, more and more achievements of language-gender studies flow into China from the western world and the study of this issue in China becomes increasingly mature thereafter. Chen Yuan (2000) examined how feminist movement contributed to transformation of vocabulary in terms of form of address. One of the examples illustrated is the advent of "Ms" in English and use of "tongzhi" in Chinese for avoiding sexism. His book is the earliest work in China studying gender language from the perspective of sociolinguistics. Zhu Wanjin (1992) contributed a lot in introducing western studies on gender-language issue. She systematically introduced three experiments conducted by Mackay and Fulkson which were designed to explore the generic use of "he". Regarding language use, Song (1998) analyzed the difference in communicative competence between women and men from six aspects: turn-taking in conversation, discourse control, taboo, question, command and politeness. Recently, special attention has been drawn to the issue of gender and media. One study investigating 8 major Chinese newspapers found that men occupied much more coverage and their speeches (91\%) were quoted much more frequently than women (9\%) (Feng, 1998). Another scholar made a comparative study on the portrayal of female politicians in 3 newspapers (China Daily, Xinmin Evening News, and the New York Times) from the perspective of coverage and image. It was found that, in China Daily and Xinmin Evening News, Chinese female leaders were portrayed unitarily as the spokesperson of state ideology without female features being mentioned, whereas the New York Times portrayed female leaders to be strong-willed, competent and educated, but it sometimes put too much emphasis on their appearance. As the author pointed out, in all of these three newspapers female leaders were marginalized while male leaders always played dominated roles (Wu, 2011). The two studies mentioned above explored media sexism from the perspective of journalism and communication without detailed linguistic analysis of the news language, which can also provide important insights into the issue of gender-language relation.

Taken together, previous studies have fruitful achievements in digging out the static linguistic sexism in the fields like vocabulary, syntax, semantics and so on. Feminist media studies in journalism and communication have also achieved significant progress. However, up until now, there were very few studies conducted to deal with this issue from a combined perspective. The purpose of the current study is to gain insights into the issue of sexism in language and its current manifestation from the perspective of linguistic analysis and media context. To this end, the authors attempt to analyze the sexism in news from two dimensions, namely, horizontal dimension (synchronic perspective) and vertical dimension (diachronic perspective).

\section{Methodology}

This study is based on the data and discourse analysis of the materials from The New York Times, one of the most authoritative newspapers in the world. Since there are no paper versions of The New York Times in China, all the news materials are found in electronic version from the official website.

In horizontal dimension, qualitative and quantitative approaches are combined to probe into the asymmetrical power distribution in news among males and females. The materials selected are from the news reports of Obama and Hillary in the 2008 US presidential election. Because they are respectively male and female rivals of equal status in the Democratic Party at that time, we can look into how sexism is reflected in different sentence patterns, dictions and reported speeches. Eighteen news reports are elected in this study, three reports each month (from January to June, because Hillary dropped out in June 2008). These reports are selected on the basis of three standards: the protagonists involve both Obama and Hillary; at least one of their names appears in the headline of the news to ensure relevance; the reports are on the first page of all the relevant searching results that month. Reporting speech is studied to expose gender discrimination by comparing the amount of direct speech and indirect speech used for different reported targets. The authors classified the sentences concerning reporting speech into 4 different modes, and calculated the percentage of each mode employed on Obama and Hillary, respectively. Table 1 is a list of selected news.

In vertical dimension, the frequencies of occurrence of marked expressions (formal marking reflected in terms of address, distributive marking reflected in the generic use of personal pronouns) are counted. The authors collect data to show how marked expressions have changed over the period from 1914 to 2014. Since this is a 100-year period and the main purpose of studying markedness phenomenon is to detect the general trend as well as positive changes, the authors choose to roughly divide these 100 years into 5 periods at the interval of every 
Table 1. The New York Times: www.nytimes.com.

\begin{tabular}{ccc}
\hline 1 & Clinton Defeats Obama in Nevada & January 19, 2008 \\
2 & Obama and Clinton Tangle at Debate & January 22, 2008 \\
3 & Kennedy Chooses Obama, Spurning Plea by Clintons & January 28, 2008 \\
4 & Is Obama a Mac and Clinton a PC? & February 4, 2008 \\
5 & Maine to Obama; Clinton Replaces Campaign Leader & February 11, 2008 \\
6 & Black Leader, a Clinton Ally, Tilts to Obama & February 15, 2008 \\
7 & Obama Pledges to Sharpen Clinton Critique & March 5, 2008 \\
8 & Obama Wins Wyoming Caucuses & March 9, 2008 \\
9 & Clinton Criticizes Obama Over His Pastor & March 26, 2008 \\
10 & A Mayor in the Obama Mold, but Backing Clinton & April 4, 2008 \\
11 & Opponents Call Obama Remarks “Out of Touch” & April 12, 2008 \\
12 & On Eve of Primary, Clinton Ad Invokes bin Laden & April 22, 2008 \\
13 & Clinton May Be Hopeful, but Obama Rolls On & May 2, 2008 \\
14 & Clinton Beats Obama Handily in West Virginia & May 14, 2008 \\
15 & Gender Issue Lives On as Clinton's Bid Wanes & May 19, 2008 \\
16 & Obama Clinches Nomination; First Black Candidate to Lead a Major Party Ticket & June 4, 2008 \\
17 & Clinton Ready to End Bid and Endorse Obama & June 5, 2008 28, 2008 \\
\hline
\end{tabular}

20 years. In data collecting the authors type key words (Mr./Mrs./Miss/Ms; he/she/he or she) and filter irrelevant information by framing specific time period (for example: $1^{\text {st }}$ January, 1914- $1^{\text {st }}$ January, 1934). On the first page of searching results (sorting by relevance), the total sum of usage in the first 10 pages will be presented and the authors record it for reference. As it is impossible to accurately count the frequencies of occurrence over every 20 years, the authors take the results in the first 10 pages as a sample. As for semantic marking, given that the complexity and difficulty of collecting data as to how the interpretations of words have changed in news context, the authors only refer to previous studies concerning semantic marking and present some relevant findings.

\section{Sexism and Speech Reporting}

\subsection{Speech Reporting}

Speech reporting plays an important role in news as it reflects the degree of objectivity and authenticity of a report. Leech \& Short (1981) classify Speech Reporting into 5 modes according to the degree of reporters' intervention and control. These modes are direct speech (DS), free direct speech (FDS), indirect speech (IS), free indirect speech (FIS) and narrative report of speech act (NRSA). Halliday (1994: p. 256) contends that quoting and reporting are not only formal variants, but also connotative variants. Thus these five modes are different from each other both in forms and in connotation. Coulmas (1985: p. 49) holds that quoting can directly reproduce the content and form from the perspective of the speaker, while reporting can only convey content and may result in incomplete interpretation. Thus the different modes of speech reporting employed by reporters on the original speakers reflect different power of discourse in the context of news, and it will be an effective tool in digging out the asymmetrical power distribution between males and females.

\subsection{Modes of Speech Reporting}

According to Leech \& Short (1981), the intensity of reporter's intervention and control differs in different mod- 
es of speech reporting. More specifically, FDS exerts the least control while NRSA exerts the most, as illustrated in Figure 1.

In direct speech, reporter exerts less control and intervention, thus the words and ideas of speakers' are faithfully expressed. While in indirect speech, reporters can manipulate discourse with their own will and understanding. Since FDS and FIS hardly appear in news reports (Xin, 2006), they are not discussed in this paper. The author only presents further introduction to DS, IS, NRSA and DS' (partial quotation) as following.

(1) Direct Speech (DS): it is expressive in that the colloquial style of the original speaker is remained. It can faithfully and objectively reproduce the exact words of speaker. Direct speech usually consists of two parts: an introductory clause which includes a subject and a reporting verb, and a reported statement which is quoted in quotation marks. For example: "I'm here," Mrs. Clinton said, "not my husband." (The New York Times, January 22, 2008)

(2) Indirect Speech (IS): it consists of two parts: an introductory clause in which the original speaker is mentioned in third person narration, and a reported statement which is presented as an object clause. In indirect speech many elements like intonation, gesture, mood, and terms of address are omitted, making the original speaker less expressive in his statement. For instance: Mr. Carson, her spokesman, said she would keep the debate issue alive until Tuesday. (The New York Times, February 15, 2008)

(3) Narrative Report of Speech Act (NRSA): this kind of reporting speech can manipulate the statement of the original speaker to the largest extent, as it only focuses on the report of narrative action rather than specific content. It focuses on "who says" rather than "who says what", e.g. As Mrs. Clinton was delivering her criticism of Mr. Obama in Ohio, a similar argument was presented to Wisconsin voters by Mr. Clinton... (The New York Times, February 15, 2008)

(4) Partial Quotation (DS'): it is a slipping mode of reporting speech between DS and IS named by Thompson (1996), also known as direct speech slipping. Though not mentioned in Leech \& Short (1981)'s major divisions, partial quotation is very common in news reports, and the authors include it in discussion. Partial quotation presents part of the original content so it can be treated as a variation of direct speech, which is marked as DS' in this paper. Examples can be illustrated in the following sentence: he added that he had sought to maintain " $a$ certain credibility" in the race. (The New York Times, January 22, 2008)

Xin (2005) and Li (2009) conducted studies on dialogicity in news discourse from the perspective of speech reporting. Based on their analysis of speaker's control in different modes of speech reporting, a modified version of the earlier figure (i.e., Figure 1) was drawn as below (Figure 2).

Davis (1985: p. 47) says: "the higher the status of the speaker, the more direct the presentation.” By looking into how female and male politicians' statements are presented, the power relations between them could be exposed.

\subsection{Analysis of Speech Reporting in The New York Times}

Since FDS and DIS are rarely seen in news reports, the authors mainly collect and analyze sentences involving DS, DS' (Partial Quotation), IS and NRSA. The number of different modes of reporting employed on Hillary and Obama is counted and the percentage of each mode is calculated as shown in Table 2.

It can be seen from the chart that DS and IS are the most frequently used speech reporting for both Obama and Hillary, but the frequency of DS employed on reports concerning Obama is $2 \%$ higher than Hillary and IS employed on Hillary is 6\% higher than Obama. Although the descriptive statistics reported here is only slightly different between the two (one reason may be due to the fact that The New York Times is Hillary's hometown newspaper), it could still shed some light on the possibility that Obama's words can be more directly heard by

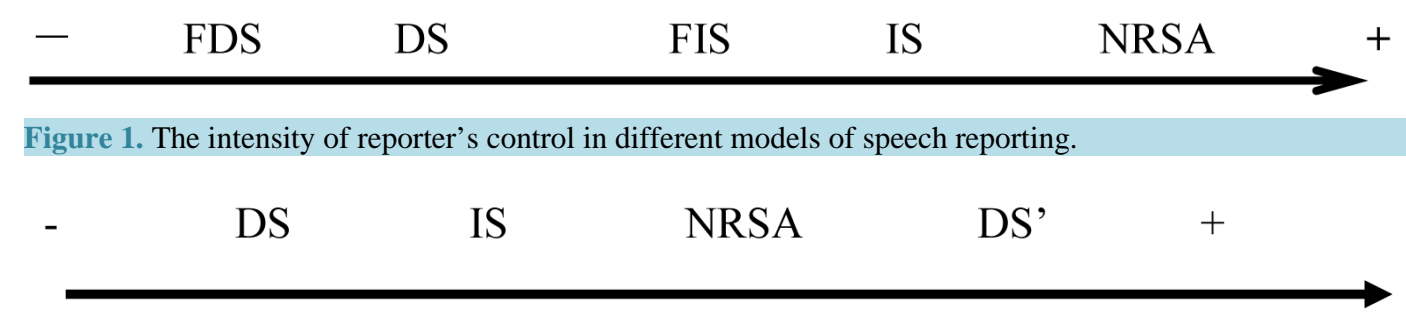

Figure 2. A modified model of the intensity of reporter's control. 
Table 2. Percentage of different modes of reporting speech in The New York Times.

\begin{tabular}{ccccc}
\hline & DS & DS' & IS & NRSA \\
\hline Obama & $47 \%$ & $14 \%$ & $29 \%$ & $10 \%$ \\
Hillary & $45 \%$ & $7 \%$ & $35 \%$ & $13 \%$ \\
\hline
\end{tabular}

the public, while Hillary's speeches are more frequently manipulated and interfered by reporters. This may consequently lead to Obama's relatively more eloquent and competent image. Examples can be found in two news reports about how Obama and Hillary criticize each other. On March 5, 2008, a report entitled Obama Pledges to Sharpen Clinton Critique writes about Obama's attack on Hillary. In this report, altogether 14 sentences, 270 words are quoted in direct speech, while 4 sentences and 122 words are quoted in indirect speech, suggesting that direct speech is more than twice the amount of indirect speech. Another report on March 26, 2008, Clinton Criticizes Obama over His Pastor, is about Hillary's attack on Obama. However, only 2 sentences, 41 words are quoted directly from Hillary's original remarks, and more arguments are presented in indirect speech (3 sentences, 74 words) which is nearly twice the amount of direct speech, making her attack relatively weaker and less impressive. As mentioned in previous section, the higher status captures more direct presentation, indicating that the gap in the frequency of DS and IS may contribute to Obama's stronger discourse power and dominance, while weaken and silence Hillary.

Another difference can be detected is that DS' employed on Obama is twice the amount employed on Hillary. As is shown earlier, reporters' intervention in this kind of speech is limited and speakers' words are relatively more faithfully and freely reproduced than IS and NRSA. The directness of DS' is only secondary to DS, therefore, the more it is used, the stronger discourse power the speaker will have. Obama's ideas are also probably channeled through DS' to the audience, while Hillary's statements are obstructed due to the lack of DS and DS'.

As for NRSA, the authors observe a slightly higher ratio in Hillary's reports. In NRSA, the focus is on action rather than on the content, so speakers' words are usually left out, making their voices unheard. Hillary's speeches are relatively more frequently presented in this mode of speech reporting, which may make her arguments appear less forceful. For example, in the following sentences collected from The New York Times: 1. Mrs. Clinton questioned Mr. Obama's electability and attacked him for saying that struggling Americans were "bitter". (April, 23, 2008) 2. Senator Hillary Rodham Clinton ended her silence on Senator Barack Obama's pastor on Tuesday, sharply criticizing Mr. Obama for not leaving the Chicago church... (March, 26, 2008) the reporter does not presents the exact content of Hillary's "question", "attack", "criticize”, but only emphasizes the speech action like "end silence". In this way her argumentations were blurred and Obama's weakness revealed in her criticism were covered.

To sum up, judging from the contrastive study of speech reporting employed on Obama and Hillary, it is possible that female politicians' discourse power is weakened, probably due to the less employment of DS and DS', and the higher occurrence of IS and NRSA. While male politicians may appear more expressive and eloquent in the news reports for their speeches and their ideas are more directly presented to the readers.

\section{Sexism and Markedness}

\subsection{Markedness Theory}

Markedness Theory can be traced back to Trubetskoy's book, The Principles of Phonology, in which it is first built to analyze the elements of phoneme. But now Markedness Theory is widely used in various fields of linguistic studies (Miao, 1995: p. 51). Markedness Theory identifies linguistic elements as marked or unmarked. Richard (1985) states that unmarked elements are more basic, natural and frequently used than marked ones. Leech (1974) holds that unmarked linguistic components are generally considered positive or neutral, while marked ones are frequently related to negative senses. Sexism in language can be clearly reflected in the asymmetry use of vocabulary (Zeng, 2009), so Markedness Theory will be an effective tool in analyzing and exposing the asymmetry between masculine expressions and feminine expressions.

According to Lyons (1977), there are three types of marking: formal marking, distributional marking, and semantic marking.

(1) Formal Marking: it sets out from the perspective of external characteristics. Generally speaking, in a pair 
of gender-opposite nouns, masculine ones are unmarked whereas feminine ones are marked with the added affixes like -ess, -ette, -rix, which may denote insignificance and humbleness (see Table 3). In this way, feminine nouns are often treated as derivations of masculine nouns (Miao, 1995). A large number of feminine nouns are created by adding affixes to masculine nouns, which may put women at a subordinate and secondary position.

(2) Distributive Marking: it refers to the different distribution ranges and the frequency of occurrence. Masculine nouns can not only be used to indicate men but also function as generic nouns, but feminine nouns have limitations in distribution. So the former is unmarked and the latter is marked. For example: chairman, businessman, salesman can be used to refer to both men and women, but chairwomen, businesswoman, saleswomen can only be used to refer to women. In terms of pronouns, Spender (1980) described a phenomenon: "she represents a woman but he is mankind. If she enters mankind she loses herself to be he." From his statement, it is assumed that masculine pronoun can be used to denote both genders or someone whose gender is unknown, but feminine pronoun can only refer to women.

(3) Semantic Marking: generally speaking, masculine nouns are neutral and generic, often associated with positive and affirmative meanings. However, feminine nouns are in a more specific and narrow sense, often containing negative meanings (Leech, 1974; Lyons, 1977; Hofmann, 1993). For example, though both bachelor and spinster refer to single person, bachelor are often regarded as free-minded and happy but spinster gives people an impression of a peculiar old woman. Semantic marking can also be found in semantic degradation or derogation (Schulz, 1975). Schulz (1975) found that many neutral or even positive female terms were sexually derogated. Some marked feminine nouns denote not only specific occupations or positions but also marital status. Examples are ambassadress, countess, empress etc.

\subsection{Formal Marking Reflected in Terms of Address}

Addressed terms are used to ascertain people's role and position in the society, reflecting and affecting people's perception towards others. However, compared with the male politicians who have the same power and influence, female politicians tend to have more addressed terms which make their positions and roles weaker and vaguer. The authors take a close look at the news reports concerning politics in The New York Times, it is found that the addressed terms of male politicians are either in their full names, or in the form of "Mr. + surname" or "title + full name/surname", with no mention of their roles as father or husband. For example, in the 2008 US Presidential Election, Barack Hussein Obama is commonly addressed as Barack Obama, Mr. Obama, and Senator Barack Obama. However, his rival in the Democratic Party, Hillary Diane Rodham Clinton, are addressed in terms like Senators Hillary Rodham Clinton, Mrs. Clinton and frequently referred to as the wife of US previous president. Other famous female leaders like Margaret Hilda Thatcher and Angela Dorothea Merkel are often addressed as Mrs. Thatcher and Mrs. Merkel, and their roles as mother, daughter, and wife are frequently mentioned in reports.

Mr. and Mrs. are respectively the honorific title of males and females, but the former is just for the sake of respect, with no indication of marital status, while the latter not only shows respect but also marital status, which puts women in a position subordinate to their husband. Women are classified into married "Mrs." and unmarried "Miss", while all men are "Mr.". Spender (1980) commented "the practice of labeling women as married or single also serves supremely sexist ends...there is no tension between the representation of women as sex objects and male ownership rights over women and this has been resolved by an explicit and most visible device of designating the married status of women". With the raised awareness of sexism in terms of address, a new word "Ms" is created to refer to all women regardless of their marital status. Heilman, Madeline (1975) conducted two experiments in a university and a high school to examine students' expectations and evaluations of the course offerings when the instructor was with no tile or tiled with "Mr./Miss/Mrs./Ms". It was found that female instructors with the title "Ms" was rated comparably to instructors titled with "Mr", while courses ascribed to Miss or Mrs. instructors were subjected to more negative judgments. This might indicate that people tend to regard "Mrs. X" or "Miss. X" less competent and intelligent while "Ms. X" equally capable as "Mr. X". Newspaper

Table 3. Examples of formal marking.

\begin{tabular}{ccccc}
\hline Masculine & Author & Manager & Administrator & Prince \\
Feminine & Authoress & Manageress & Administratrix & Princess \\
\hline
\end{tabular}


agents have paid attention to this issue, and "Ms" have become more and more popular in news reports. In The New York Times many influential female politicians like Angela Dorothea Merkel are now frequently addressed as "Ms. + surname". Below is a table of numerable data collected from The New York Times, showing how the use of "Mr." "Mrs." "Miss" "Ms" have developed and changed through the past century (see Table 4).

We can see from Figure 3 that Mr. is much more frequently used than the other three terms, reflecting that males are still dominant in politics. But an increase in the use of the female titles is also observed, showing that females are gaining more and more power compared with the past. Notably, as illustrated in Figure 4, the use of "Ms" surges at a fast rate in the last decades (during the period of 1994-2014), indicating that gender-language issue is getting more and more attention from the news media in recent years and is handled cautiously.

\subsection{Distributive Marking Reflected in Personal Pronouns}

Marking in terms of address belongs to formal marking, in this part we will explore distributive marking by analyzing personal pronouns. Personal pronouns include "he”, "him”, "himself", "she”, "her", "herself” etc. In English, "he" can be used for both male and female. For instance, in the sentence "one should do the best he can", he refers to both men and women. However, "she" can only be used to refer to female, so masculine pronouns are distributed much more widely than feminine pronouns. Liu (2002) selected 1284 sentences with the third person pronouns in his survey and found that more than $75 \%$ of the sentences adopted the generic use of "he", "his" and "him". To find out the distribution of personal pronouns in news context and positive changes taking place during the past 100 years, the authors collect data about "he", "she" and "he or she" in The New York Times, and tabulate information as in Table 5.

As can be seen from Figure 5 and Figure 6, "he" is dominant in coverage, but the frequency of occurrence

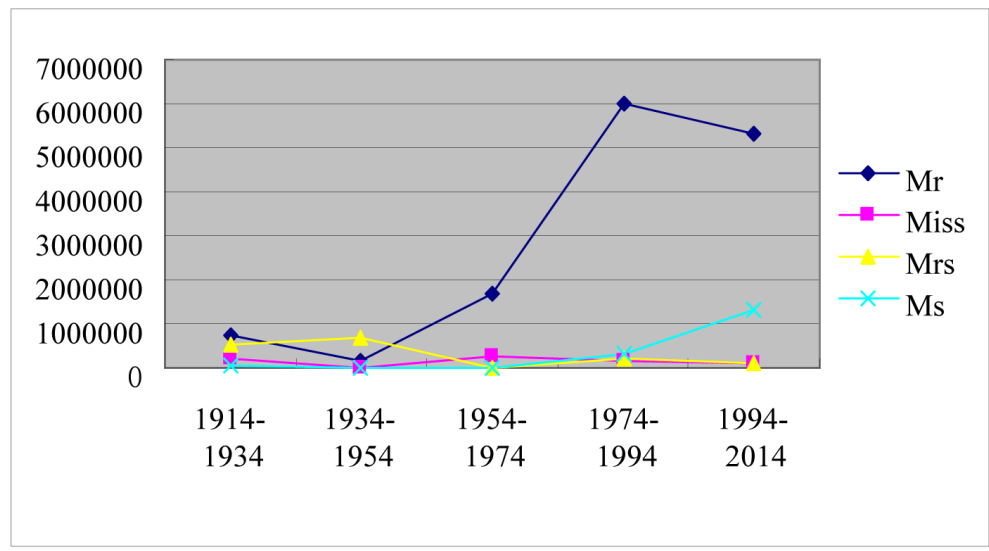

Figure 3. The number of occurrence for the addressed terms.

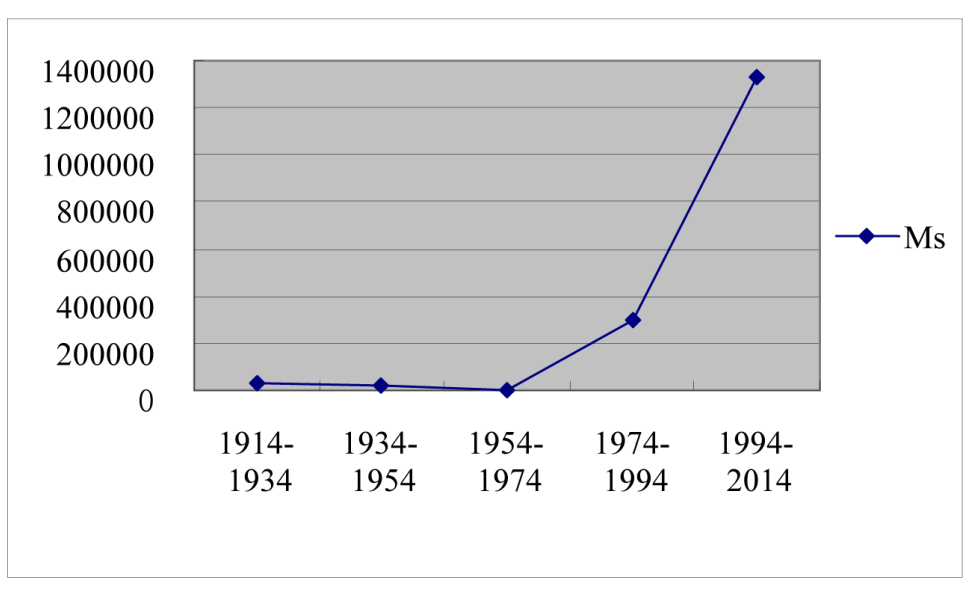

Figure 4. The number of occurrence for "Ms". 


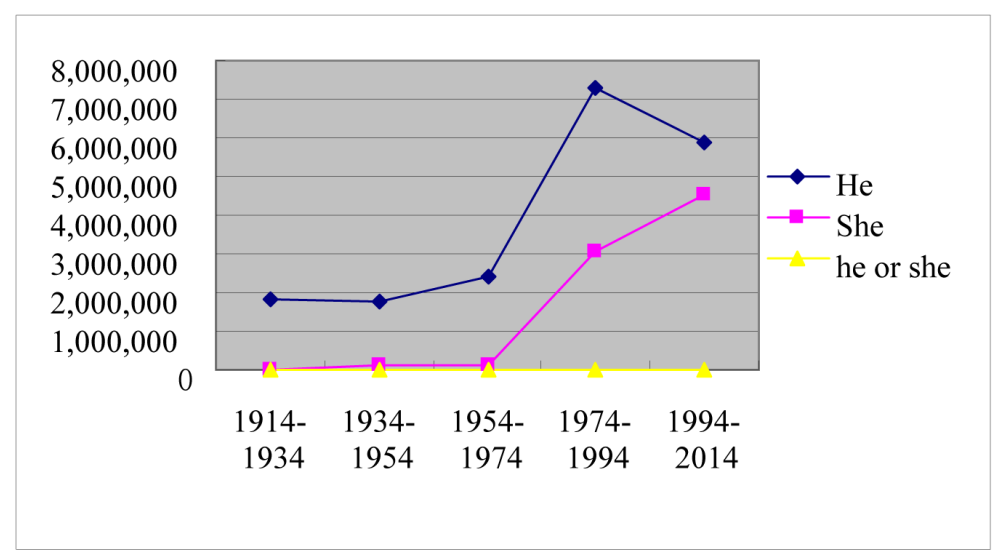

Figure 5. The number of occurrence for personal pronouns.

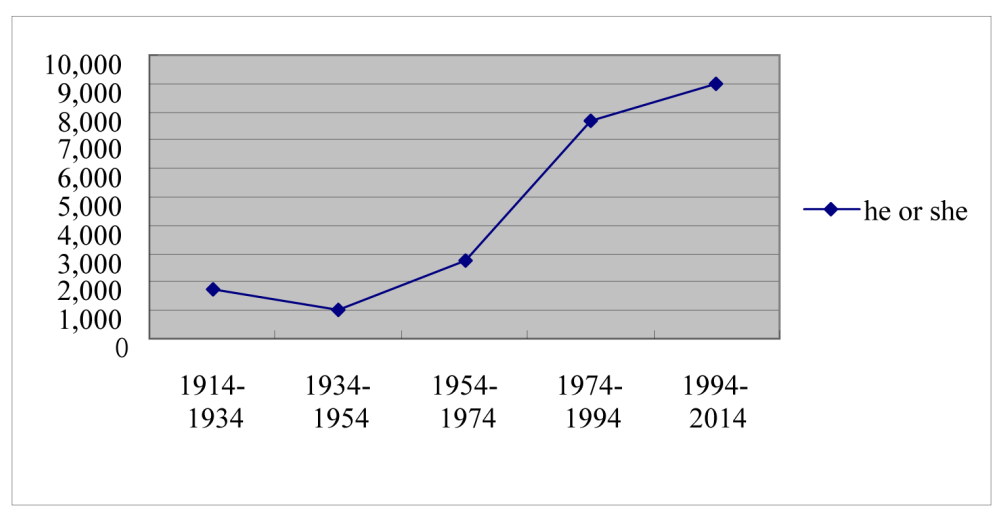

Figure 6. The number of occurrence for "he or she".

Table 4. The number of occurrence for the addressed terms (i.e., Mr., Miss, Mrs., and Ms) in The New York Times from 1914 to 2014.

\begin{tabular}{cccccc}
\hline & $1914-1934$ & $1934-1954$ & $1954-1974$ & $1974-1994$ & $1994-2014$ \\
\hline Mr. & 725,000 & 136,000 & $1,660,000$ & $6,010,000$ & $5,320,000$ \\
Miss & 227,000 & 279,000 & 260,000 & 164,000 & 95,600 \\
Mrs. & 501,000 & 681,000 & 613,000 & 217,000 & 117,000 \\
Ms & 27,100 & 18,400 & 21,100 & 296,000 & $1,330,000$ \\
\hline
\end{tabular}

Table 5. The number of occurrence for the personal pronouns (i.e., he, she, and he/she) in The New York Times.

\begin{tabular}{cccccc}
\hline & $1914-1934$ & $1934-1954$ & $1954-1974$ & $1974-1994$ & $1994-2014$ \\
\hline He & $1,830,000$ & $1,780,000$ & $2,430,000$ & $7,290,000$ & $5,910,000$ \\
She & 204 & 116,000 & 139,000 & $3,050,000$ & $4,540,000$ \\
He or She & 1770 & 998 & 2720 & 7660 & 8980 \\
\hline
\end{tabular}

of "she" has experienced sharp increase since 1974. This implies that although the generic use of "he" makes women invisible, with the continuous struggle for gender equality, females begin to gain more and more spotlight from the news media. Noteworthily, "he or she” appears in news reports more and more frequently, which will reduce the generic use of masculine pronouns. For example, a report in 2008 under the title of "Economic Review: Stop the World (and Avoid Reality)" used "she or he" instead of "he" to refer to the possible male or 
female leaders:

"If so, the next president faces a huge challenge. Briefly put, she or he will need to find ways to make Americans more comfortable with globalization."

Although expressions like "he or she", "his or her" is cumbersome and not as convenient as the generic "he", but they will reduce misinterpretation and show more respect for gender equality.

\subsection{Semantic Marking Reflected in Terms Denoting Professions}

Since it is difficult and complex to collect data concerning semantic changes in news context, the authors here just review some previous studies on this point and relate them to this paper. Semantic marking here is analyzed from the perspective of terms denoting professions.

Gibbon (1999) found in her study that when reading a riddle (a boy whose father has already died in an accident was sent to hospital, but the surgeon refused to operate on him because "he's my son") people are confused because they have a stereotyped image of surgeon and have difficulty relating surgeon to women. Females are always semantically absent from professional and prestigious occupations which are usually considered exclusive to males. For example: lawyer, pilot, doctor, judge, mayor, governor, administrator etc. When these occupations are taken by women, people plus "woman", "lady", "female" in front of these words (Wang, 2005). This practice establishes man as the norm while woman as derivative. Furthermore, many female terms which started out as harmless or positive undergo semantic degradation while their masculine counterparts do not (Schulz, 1975). Governess, which referred to female ruler at the very first, can only be used to refer to family tutor now. But "governor" remains its original meaning of lord. Other words like duchess, mayoress not only mean the position itself but also suggest marital status, denoting "the wife of". Semantic degradation shows explicitly that women are oppressed by language sexism.

However, it is nice to see that the news media have realized this problem. As more and more women get involved in politics and occupy important positions, new words are created to empower woman. "Chairwoman", "Congresswoman", "spokeswoman" etc. come into being. These words accept woman as equally competent and capable, putting women and men in equal positions.

Marking in terms of address, personal pronouns and semantics shows that language in itself is sexist. While the results of descriptive statistics based on percentage of the usage from the past 100 years in The New York Times suggests something positive: people have realized the problem of sexism and have made effort to reduce its negative influence.

\section{Conclusions and Limitations}

This paper adopts a comparative and descriptive study of the news reports concerning female and male politicians in The New York Times to probe into sexism in news language. From a two dimensional study: vertical study of the markedness phenomenon during the period 1914-2014, and horizontal study of the modes of speech reporting employed on Obama and Hillary in the 2008 US Presidential Election, several preliminary findings have come to light. The synchronic study suggests that the modes of speech reporting which are manipulated by reporters may give male politicians more discourse power. The diachronic study of markedness phenomena indicates the development and change of the sexism in vocabulary: though language is sexist in itself, positive changes are taking place with the raised awareness of gender equality.

It should be pointed out that, there are some limitations in the present study which require future exploration. Firstly, the research materials are all taken from the official website of The New York Times, and the news reports are mainly concerned with Obama and Hillary, with no investigations into other newspapers and politicians, which limit the generality of our findings. Moreover, since Hillary is a New Yorker, The New York Times shows more favor to her compared with other newspapers, so the effect of sexism is impaired in its news reports. Therefore, the gaps between data are smaller and vaguer. Further studies are required to explore this issue by expanding corpus, touching upon more newspapers and politicians so that the conclusions can be supported by more solid evidence from variable sources of materials. Secondly, more aspects of sexism in news are also remained for exploration, such as nominalization, passivization and rhetoric devices employed on opposite genders. Finally, since this paper is only a preliminary descriptive study, rather than experimental study, the results lack solid evidence. Further statistical analysis is required for more objective results and more solid evidence from empirical studies such as interview and questionnaire should be obtained to evaluate the public perception towards sexism in news. 


\section{References}

Attenborough, F. (2013). Sexism Re-Loaded ... or Sexism Re-Presented? Irrelevant Precision and the British Press. Feminist Media Studies, 13, 693-709. http://dx.doi.org/10.1080/14680777.2012.700524

Attenborough, F. (2014). Jokes, Pranks, Blondes and Banter: Recontextualising Sexism in the British Print Press. Journal of Gender Studies, 23, 137-154. http://dx.doi.org/10.1080/09589236.2013.774269

Chen, Y. (2000). Sociolinguistics. Beijing: The Commercial Press.

Coulmas, F. (1985). Direct and Indirect Speech: General Problems and Problems of Japanese. Journal of Pragmatics, 9, 41-63.

Davis, H. (1985). Discourse and Media Influence. In T. A. van Dijk (Ed.), Discourse and Communication: New Approaches to the Analysis of Mass Media Discourse and Communication. Berlin: Walter de Gruyter.

Feng, Y. (1998). Women's Existence in News: A Research Report of 8 Major Chinese Newspapers. Zhejiang Academic Journal, 2, 81-85.

Gibbon, M. (1999). Feminist Perspective on Language. Harlow: Addison Wesley Longman.

Halliday, M. A. K. (1994). An Introduction to Functional Grammar. London: Edward Arnold.

Heilman, M. E. (1975). Miss, Mrs., Ms., or None of the Above. American Psychologist, 30, 516-518. http://dx.doi.org/10.1037/0003-066X.30.4.516

Hofmann, Th. R. (1993). Realms of Meaning. London: Longman.

Jesperson, O. (1923). Growth and Structure of English Language. Oxford: Basil Blackwell Ltd.

Lakoff, R. (1975). Language and Women's Place. New York: Harper \& Row.

Leech, G. (1974). Semantics. Harmondsworth: Penguin Books.

Leech, G. N., \& Short, M. H. (1981). Style in Fiction. London: Longman.

Li, J. F. (2009). On Reported Speech and the Dialogic Nature of News Texts. Journal of Beijing International Studies University, 2, 8-16.

Liu, H. J. (2002). Sexism in Language. Journal of Xi'an International Studies University, 10, 35-39.

Lyons, J. (1977). Semantics. London: Cambridge University Press.

Megarry, J. (2014). Online Incivility or Sexual Harassment? Conceptualizing Women's Experiences in the Digital Age. Women's Studies International Forum, 47, 46-55. http://dx.doi.org/10.1016/j.wsif.2014.07.012

Miao, X. W. (1995). A Probe into the Sexism in English from the Perspective of Markedness Theory. The Journal of Sichuan International Studies University, 3, 51-55.

Richard, J. (1985). Longman Dictionary of Applied Linguistics. London: Longman.

Sapir, E. (1986). Language, Culture, and Personality. Oakland, CA: University of California Press.

Schulz, M. (1975). The Semantic Derogation of Woman. New York: Thorne and Henley.

Song, H. Y. (1988). Gender Stereotype and Language Use in Interaction. Journal of Foreign Languages, 2, 58-63.

Spender, D. (1980). Man Made Language. London: Routledge and Paul.

Steyer, I. (2014). Gender Representations in Children's Media and Their Influence. Campus-Wide Information Systems, 31, 171-180.

Thompson, G. (1996). Voices in the Text Discourse Perspectives on Language Reports. Applied Linguistics, 17, 501-530. http://dx.doi.org/10.1093/applin/17.4.501

Toffoletti, K. (2007). How Is Gender-Based Violence Covered in the Sporting News? An Account of the Australia Football League Sex Scandal. Women's Studies International Forum, 30, 427-438. http://dx.doi.org/10.1016/j.wsif.2007.07.004

Wang, X. X. (2005). Sexism Reflected in Language Use. Shandong Foreign Languages Teaching Journal, 4, 34-37.

Wright, K. A. M., \& Holland, J. (2014). Leadership and the Media: Gendered Framings of Julia Gillard's "Sexism and Misogyny” Speech. Australian Journal of Political Science, 49, 455-468. http://dx.doi.org/10.1080/10361146.2014.929089

Wu, Y. M. (2011). Cross-Culture Interpretation of the Female Leader's Image in Chinese and American Political News. Journalism \& Communication, 1, 17-21.

Xin, B. (2005). Critical Discourse Analysis: Theory and Application. Shanghai: Shanghai Foreign Language Education Press.

Xin, B. (2006). Comparative Analysis of the Reporting Mode and News Source in China Daily and the New York Times. Foreign Languages and Their Teaching, 3, 1-4.

Zeng, Y. (2009). Markedness Theory and Sexism in English Vocabulary. Journal of Language and Literature Studies, 4, 1-3. Zhu, W. J. (1992). Introduction to Sociolinguistics. Hunan: Hunan Education Press. 
Scientific Research Publishing (SCIRP) is one of the largest Open Access journal publishers. It is currently publishing more than 200 open access, online, peer-reviewed journals covering a wide range of academic disciplines. SCIRP serves the worldwide academic communities and contributes to the progress and application of science with its publication.

Other selected journals from SCIRP are listed as below. Submit your manuscript to us via either submit@scirp.org or Online Submission Portal.
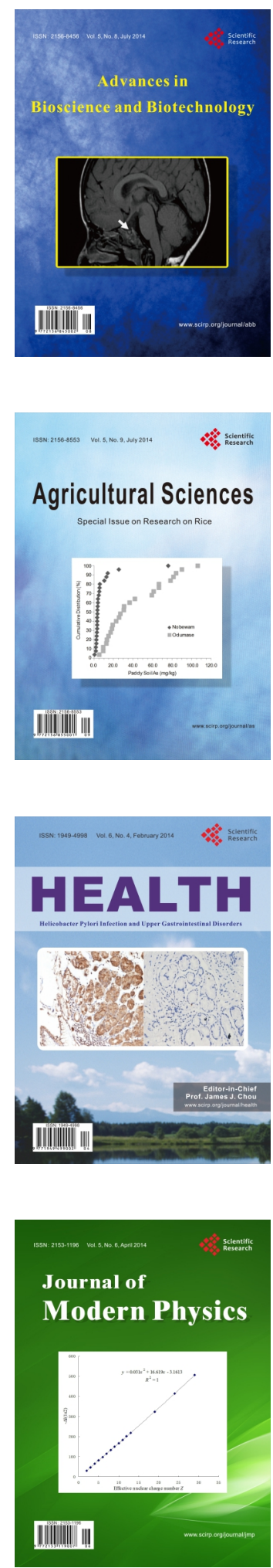
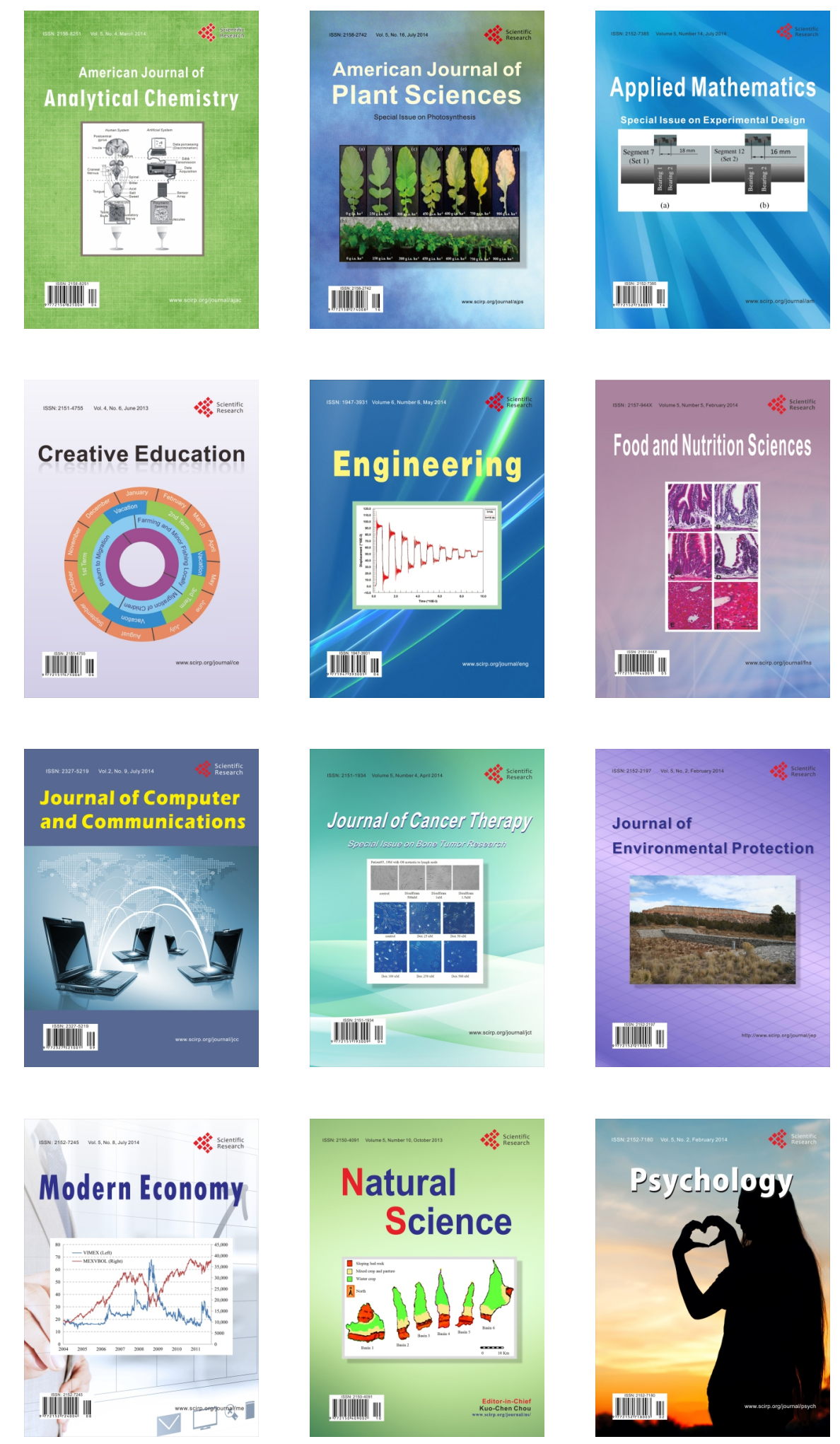